\title{
A CONSTRUÇÃO DO CONHECIMENTO AGROECOLÓGICO NO TERRITÓRIO CENTRAL DO RIO GRANDE DO SUL: UMA EXPERIÊNCIA BASEADA NA METODOLOGIA CAMPESINO A CAMPESINO
}

\author{
Marielen Priscila Kaufmann ${ }^{1}$ \\ Nayara Pasqualotto ${ }^{2}$ \\ Mauricio Machado Sena ${ }^{3}$
}

\begin{abstract}
RESUMO
Primando, sobretudo, pela valorização dos conhecimentos dos agricultores como um aspecto primordial no estudo e compreensão da dinâmica dos agroecossistemas, este artigo apresenta a experiência da utilização da metodologia Campesino a campesino (CAC), para promover a construção do conhecimento agroecológico entre os agricultores ecologistas do Território Central do Rio Grande do Sul. Sob este enfoque, realizaram-se seis oficinas sobre temas recorrentes na produção ecológica de alimentos, tais como a fruticultura, horticultura e pecuária leiteira ao longo do ano de 2015. Ademais, o artigo objetiva analisar as potencialidades e fragilidades do emprego desta ferramenta metodológica no contexto sulriograndense. Os resultados desta experiência nos indicam que há necessidade de maior discussão sobre o CAC nas instituições de ensino, bem como nas instituições de extensão rural, visto que há uma resistência, por parte da comunidade acadêmica e dos extensionistas rurais a compreender e valorizar o agricultor como um ator de desenvolvimento.
\end{abstract}

Palavras-chave: Agroecologia, campesino a campesino, extensão rural agroecológica, troca de experiências.

\section{CONSTRUCTION OF AGROECOLOGICAL KNOWLEDGE IN THE RIO GRANDE DO SUL CENTRAL TERRITORY: AN EXPERIENCE BASED ON CAMPESINO TO CAMPESINO METHODOLOGY}

\begin{abstract}
Striving, especially for the valorization of farmers' knowledge as a primordial aspect in the study and understanding of the dynamics of agroecosystems, this paper presents the experience of the Campesino a Campesino (CAC) methodology to promote the construction of agroecological knowledge among ecological farmers of the Rio Grande do Sul Central Territory. From this approach, six workshops happen on recurrent themes in organic food production, such as fruit growing, horticulture

\footnotetext{
${ }^{1}$ Graduada em Engenharia Florestal (UFSM). Mestrado em Extensão Rural (UFSM). Doutoranda em Desenvolvimento Rural (UFRGS).E-mail: marielenpk@yahoo.com.br

2 Graduada em Geografia (UNIOESTE). Mestrado em Desenvolvimento Regional (UTFPR). Doutora em Extensão Rural (UFSM). E-mail: nayarapasqualotto@hotmail.com

${ }^{3}$ Graduado em Jornalismo (UFSM). Mestrado em Extensão Rural (UFSM). Doutorando em Extensão Rural (UFSM). E-mail: jornal.sena@gmail.com
} 
and dairy farming throughout the year 2015. In addition, the paper aims to analyze the potentialities and fragilities of this methodological tool in the South-Rio Grande do Sul context. The results of this experiment indicate that further discussion about CAC in educational institutions is needed, as well as in rural extension institutions, since there is a resistance on the part of the academic community and rural extension agents to understand and value the farmer as a development actor.

Key-words: Agroecology, campesino a campesino, agroecological rural extension, experience exchange.

\section{INTRODUÇÃO}

Nas últimas décadas, instituições oficiais de extensão rural, entidades da sociedade civil e a academia têm orientado grandes esforços para promover uma agricultura de base ecológica, tendo os pressupostos da Agroecologia como referência. Isto porque, Agroecologia é considerada um campo de conhecimento científico que orienta e subsidia as agriculturas sustentáveis (ALTIERI, 2001) e que se nutre dos mais variados conhecimentos de diferentes ciências, principalmente os saberes populares, sob uma perspectiva multidisciplinar (CAPORAL, et al., 2006).

No intuito de estimular a pesquisa, extensão e o ensino da Agroecologia, o Núcleo de Estudos em Agroecologia, Agrobiodiversidade e Sustentabilidade Prof. José Antônio Costabeber (NEA-UFSM) foi fundado em 2014, tendo suas origens a partir de trabalhos desenvolvidos no Grupo de Agroecologia Terra Sul - GATS.

As atividades do grupo visam mapear as ações desenvolvidas, relacionadas à aplicação dos princípios da Agroecologia, procurando identificar os pontos de convergência, as metodologias utilizadas e as dificuldades enfrentadas, a fim de promover a integração das instituições na troca de experiência e união de esforços em ações que integrem pesquisa, extensão e educação, procurando articular as diversas formas de conhecimento e aplicá-las às práticas sociais. O NEA-UFSM também objetiva a formação continuada em Agroecologia com uma abordagem crítico-construtivista e interdisciplinar, além de contribuir na construção do conhecimento a partir das condições reais vivenciadas nas unidades de produção agrícolas familiares.

A equipe, formada por professores, técnicos e estudantes de diferentes formações acadêmicas, em um primeiro momento, desenvolveu ações com intuito de consolidar parcerias em torno do Desenvolvimento Sustentável na Região Central do Rio Grande do Sul (RS). Por isso, as ações foram desenvolvidas no âmbito dos 34 municípios que fazem parte do território central do estado do RS, delimitado pela Secretaria de Desenvolvimento Territorial do Ministério do Desenvolvimento Agrário (SDT-MDA): Agudo, Cacequi, Cachoeira do Sul, Capão do Cipó, Dilermando de Aguiar, Dona Francisca, Faxinal do Soturno, Formigueiro, Jari, Mata, Nova Esperança do Sul, Nova Palma, Quevedos, Santiago, São João do Polêsine, São Martinho da Serra, Silveira Martins, Tupanciretã, Unistalda, Vila Nova do Sul, Itaara, Ivorá, Jaguari, Júlio de Castilhos, Novo Cabrais, Paraíso do Sul, Pinhal Grande, Restinga Seca, Santa Maria, São Francisco de Assis, São Pedro do Sul, São Sepé, São Vicente do Sul e Toropi.

Esta região tem 650.500 habitantes, dos quais 119.811 estão na área rural, onde vivem cerca de 29.808 agricultores familiares, 1.248 famílias assentadas, 237 famílias de pescadores e cinco comunidades quilombolas (MDA, 2012). Segundo estudo realizado por Neumann (2003), o território central é predominantemente 
baseado na agricultura familiar, apresentando grande diversidade agroecossistêmica, onde há ocorrência de diferente topografia típica.

Em 2012, iniciaram-se as incursões aos municípios do território central a fim de elaborar um esboço do contexto da ecologização dos agroecossistemas. Inicialmente, foram contatados os representantes municipais que estão relacionados com a extensão rural e a assistência técnica, tais como a Emater/RS-Ascar, as prefeituras e as secretarias municipais, Organizações não Governamentais (ONGs) e associações. Com estas informações, foram localizadas 61 agroecossistemas em transição agroecológica em 16 municípios da região central (KAUFMANN, et al., 2015).

O mapeamento foi refeito em 2014 , sob as mesmas bases metodológicas, quando foram identificados 93 agroecossistemas considerados em transição agroecológica no território central do RS. Destes, a maioria já pertencia à rede de contatos e relacionamento dos membros do NEA-UFSM (PASQUALOTTO, 2018). A partir deste mapeamento foi possível identificar experiências consideradas referências na promoção da agricultura ecológica, que puderam ser acompanhadas desde $o$ ano de 2014 e que participaram de uma troca de saberes, facilitadas pela equipe do NEA-UFSM, as quais foram baseadas na metodologia Campesino a Campesino (CAC). O objetivo deste artigo é apresentar os resultados desta experiência, desenvolvida durante o ano de $2015 \mathrm{com}$ oito famílias de agricultores ecologistas do território central do RS e analisar a contribuição do CAC para a promoção da extensão rural agroecológica, identificando as potencialidades e fragilidades do emprego desta ferramenta metodológica no contexto sulriograndense.

\section{A EXTENSÃO RURAL A PARTIR DA AGROECOLOGIA}

Os princípios agroecológicos aparecem como meio de proporcionar à agricultura mecanismos mais sustentáveis de gestão. Esses são apreendidos como um novo paradigma de desenvolvimento para o meio rural, os quais surgem como uma matriz disciplinar pautando-se em diversas áreas do conhecimento (CAPORAL, COSTABEBER e PAULUS, 2006). Dessa forma, os autores Cotrim e Dal Soglio (2016) consideram a transição agroecológica como um processo gradual e que se baseia nos conhecimentos que são construídos neste processo, sobretudo na interlocução dos saberes dos agricultores e dos conhecimentos científicos (COTRIM; DAL SOGLIO, 2016).

Sendo assim, a Agroecologia não proporciona uma teoria fechada sobre suas metodologias, indicando a melhor opção ou uma fórmula exata para construir e validar conhecimentos. Porém, indica a necessidade de buscar através dos saberes e experiências já acumulados, ou através da ação participativa e aprendizagem, uma forma de estudo e intervenção que proporcione a ascensão das transformações sociais necessárias para lançar padrões mais sustentáveis de produção e consumo (CAPORAL, 2006).

Fazendo parte dos princípios que norteiam a Agroecologia, estão as questões relacionadas ao protagonismo assumido pelos agricultores, os quais são agentes ativos nos agroecossistemas, responsáveis pelas transformações na produção e comercialização. Neste contexto, cabe a extensão rural agroecológica o papel de contribuir com o processo de desenvolvimento no campo pautado no bem estar social das comunidades, na participação ativa de seus atores e na preocupação com os recursos naturais (BORGES, 2012).

Caporal e Dambros (2017), ao analisarem a atuação da extensão rural sob a perspectiva da Agroecologia, sinalizam a importância das questões sociais e 
culturais para o sucesso das ações extensionistas, a partir do enfoque agroecológico, relatando que este se apresenta como um desafio à prática profissional dos técnicos e extensionistas. Isso porque, a problemática no campo está além das questões técnicas e a redução a esse tipo de abordagem gera solução de problemas pontuais, que não são efetivas.

De acordo com Caporal (2003), a extensão rural agroecológica pode ser definida como um mecanismo de intervenção de função educativa e transformadora, o qual se pauta em metodologias participativas, possibilitando o desenvolvimento de práticas sociais que ressaltam os atores do processo como principais agentes do conhecimento. O seu principal objetivo é o de

\begin{abstract}
[...] alcançar um modelo de desenvolvimento socialmente equitativo e ambientalmente sustentável, adotando os princípios teóricos da Agroecologia como critério para o desenvolvimento e seleção das soluções mais adequadas e compatíveis com as condições específicas de cada agroecossistema e do sistema cultural das pessoas envolvidas com o seu manejo (CAPORAL, 2003, p.6)
\end{abstract}

Embora se tenha um acumulo teórico acerca da contribuição das questões sociais e culturais enfocados nos saberes dos agricultores, ainda a questão técnica adquire relevância na atividade extensionista. Melo e Pinheiro (2017), ao estudarem o viés da extensão rural nos últimos 30 anos, concluem que a abordagem da eficiência está associada à dimensão técnica, associando a atividade extensionista à difusão de tecnologias e ao aumento da produtividade. Eles propõem a emergência de eficiência adquirindo outras lógicas tais como a social, cultural, solidária, ambiental, formativa e subjetiva, envolvidas nos objetivos e necessidades de cada agricultor, o que de certa forma dialoga com as premissas da extensão rural agroecológica.

Siliprandi (2002) ressalta os desafios enfrentados para a efetivação de uma extensão rural agroecológica que abarque várias dimensões da sustentabilidade. De acordo com a autora, o maior deles pode consistir na desconstrução da forma como olhamos para o rural, e entender que é necessário uma teia social que agregue diferentes atores, valorizando-os, de forma democrática e equitativa.

Neste sentido, cabe ao extensionista ou agroecólogo ser um facilitador de ações que promovam o diálogo entre os conhecimentos científicos e os saberes das populações rurais, em prol de construir novos saberes capazes de desenvolver soluções concretas para a sua realidade, sempre pautada pela sustentabilidade em sua ampla concepção. A partir deste panorama, as ferramentas da pesquisa participativa são fundamentais para alcançar os objetivos da extensão rural agroecológica, assim como para a construção dos conhecimentos agroecológicos e a pesquisa em Agroecologia (DAL SOGLIO, 2017).

A crescente utilização das ferramentas metodológicas participativas decorre da percepção de que as ferramentas de trabalho, na extensão rural clássica, atendem de maneira parcial a demanda da ampla maioria dos agricultores brasileiros, ou seja, os agricultores familiares (CAPORAL; DAMBROS, 2017; COTRIM, 2017). Desse modo, as ONGs e as instituições de pesquisa têm proposto uma série de técnicas e modelos que reivindicam mais espaço para as vozes dos trabalhadores e para a sua real participação, facilitando, assim, que estes estejam empoderados do processo de desenvolvimento que estão inseridos e construindo (COTRIM, 2017). 


\section{METODOLOGIA CAMPESINO A CAMPESINO}

A partir da experiência exitosa de grupos latino-americanos na tentativa de construir novas formas de extensão e pesquisa, nasceu o que hoje se denomina Campesino a Campesino. Existe uma discussão teórica acerca do desenvolvimento do termo, se metodologia, se ferramenta, movimento ou programa. Não cabe aqui apresentar todas as justificativas e usos, pois em cada situação e em cada país onde o CAC tem se desenvolvido, ele recebe um status e uma perspectiva diferente e condizente com o que vem sendo realizado. Para efeitos deste artigo, utilizar-se-á a referência ao CAC como uma metodologia, assim como na sua descrição original e não traduzido (Campesino a Campesino é o termo na língua espanhola, cuja tradução literal para o português é "Camponês a Camponês").

Eric Holt-Giménez (2008), um dos primeiros pesquisadores que sistematizou as experiências e realizou um estudo das origens e caminhos do CAC, não o desvincula de uma história de luta cultural de resistência dos camponeses da América. A metodologia CAC foi inspirada nas formas de transmissão de conhecimentos e o processo de experimentação que as comunidades indígenas maias e astecas mantinham. É justamente na América Central e sul do México que, a partir da década de 1960, inicia-se o processo de recuperação destas metodologias que foram sendo incorporadas pelas instituições e movimentos sociais envolvidos com a questão agrícola nestes países. Conceitualmente, significa uma forma participativa de promoção e melhoramento dos sistemas agrícolas, partindo do princípio que a participação e o empoderamento são elementos intrínsecos à sustentabilidade, centrado na própria iniciativa e no protagonismo dos agricultores (GIMÉNEZ, 2008).

Essa metodologia consiste no intercâmbio de conhecimentos e do processo de experimentação combinados com uma rede de compartilhamentos de informações. Todo o processo é coordenado e dirigido pelos próprios agricultores. Muito se aproxima das teorias postuladas por Paulo Freire (1983), quando defende relações horizontais entre o educador que aprende e é, assim, educando e, o educando que ensina e é, portanto, também educador. Além disso, promove a diversidade e multiplicidade de conhecimentos provindos dos próprios agentes ou atores do campo.

Historicamente, os primeiros relatos de utilização, e que tratam sobre o surgimento desta metodologia, tem suas origens nas comunidades Mayas Kaqchikeles, de Chimaltenagos, na Guatemala. Gimenez (2008) relata que a metodologia surgiu a partir da experiência de um técnico extensionista que, não compreendendo o idioma local, sendo que somente alguns poucos camponeses falavam o espanhol, percebeu que a maneira de fazer os agricultores conhecerem suas experiências poderia ser feita por meio de demonstração e experimentação das práticas por alguns camponeses. Constatando os rápidos e satisfatórios resultados, os agricultores experimentadores encorajaram-se a compartilhar suas experiências com vizinhos e outros agricultores.

O método tem sido utilizado em vários países da América Latina, como Nicarágua, El Salvador, Guatemala, México e Cuba, onde tem apresentado resultados importantes nos seus processos de transição agroecológica. Inclusive em Cuba a metodologia tomou proporções nacionais, onde é denominada de Movimento Agroecológico (SOSA et al., 2010). A premissa é trabalhar com a família, envolvendo todos os membros nas atividades, na formulação, na experimentação em si e na socialização com a comunidade. Esta família é considerada um 
experimentador e um promotor de suas práticas ecológicas e no momento de receber outras famílias no seu agroecossistema, tem a oportunidade de socializar os conhecimentos e, a partir do feedback dos outros agricultores,ensinar, aprender e/ou melhorar suas práticas.

Em Cuba (SOSA et al., 2010), o CAC segue três passos básicos na fase de implantação: a problematização - onde são identificados, por meio de diagnóstico rural participativo, os problemas concretos que precisarão ser atacados; a experimentação - adoção de uma prática a fim de solucionar o problema identificado; a promoção e multiplicação das práticas - por meio dos intercâmbios se socializam as experiências exitosas. O autor destaca que práticas simples, de baixo custo e com resultados rápidos são importantes para o efeito entusiasta necessário à credibilidade do processo.

Ademais, Gimenéz (2008) afirma que a literatura sobre o desenvolvimento sustentável descreve o método CAC como uma solução inovadora e efetiva para a transmissão de técnicas e saberes. No entanto, o autor faz uma crítica, uma vez que a "transferência de tecnologia" acaba sendo mais valorizada do que o intercâmbio cultural onde se geram e compartilham os saberes.

Dessa forma, o CAC traz uma série de oportunidades como a possibilidade da formação de lideranças, o fortalecimento das organizações e o desenvolvimento a partir de aplicação de técnicas menos agressivas ao meio ambiente. Além disso, apresenta-se como uma ferramenta onde todas as suas fases de aplicação se estruturam de forma participativa, começando com a pesquisa do tema, a organização do dia, a realização da experiência e a avaliação dos resultados.

Ademais, o CAC é uma referência na divulgação de conhecimento técnico principalmente em agroecossistemas em transição agroecológica, onde a substituição dos agrotóxicos traz a necessidade da introdução de novas práticas adequadas de cultivo, controle de pragas e danos, através da promoção do uso de preparados biodinâmicos, adubação verde, estratégias de conservação do solo e da água e promoção da biodiversidade aliadas à produção de alimentos nutritivos e saudáveis.

Em Cuba, por exemplo, onde a metodologia CAC recebeu o apoio institucional e se massificou, em vinte anos registrou-se o aumento gradativo, de 3100 famílias envolvidas no CAC em 2000, para o total de 130 mil famílias no ano de 2017 (MACHÍN, 2017). Este número representa aproximadamente $46 \%$ da área rural do país, cujas famílias se encontram utilizando os conceitos agroecológicos na produção agrícola. Ademais, o autor relaciona o aumento da produção ecológica de alimentos na ilha ao Movimento CAC, que além de mobilizar agricultores e técnicos, também está ingressando nas escolas e universidades, nas quais são formados profissionais das mais diversas áreas do conhecimento, garantindo, assim, promissoras perspectivas para o CAC e a Agroecologia no país (MACHíN, 2017).

\section{PROCEDIMENTOS METODOLÓGICOS}

Numa tentativa real de aproximação com as experiências latinoamericanas, as oficinas e dias de campo, realizados pelo NEA-UFSM, são orientados pela metodologia Campesino a Campesino (CAC), que pretende fomentar a utilização de metodologias alternativas que garantam a participação efetiva dos agricultores nas tomadas de decisões e devidas orientações produtivas. Além disso, se apresenta como uma metodologia que empodera os agricultores junto às comunidades e na divulgação do conhecimento, através de uma proposta pedagógica em que um agricultor "especialista" socializa conhecimentos e 
experiências a outros agricultores, a fim de que possam ser discutidos, analisados e experimentados.

As oficinas e dias de campo, relatadas neste artigo, aconteceram durante o ano de 2015. Elas ocorreram diretamente nos agroecossistemas de agricultores ecologistas que se destacaram quanto ao avanço nas técnicas e demais aspectos da transição agroecológica, caracterizando-se assim como propriedades-referência para outras experiências.

Ao todo foram realizadas seis atividades, as quais se denominaram oficinas, em cinco diferentes municípios da região central do RS, cada uma abordou uma temática diferente. No entanto, os temas abordados foram correspondentes com as demandas levantadas por cada município. Apesar de o público alvo ser, principalmente, agricultores e agricultoras da região, houve participação de diversos atores envolvidos no processo, desde estudantes de graduação, pós-graduação, professores universitários, técnicos e extensionistas de ATER.

A primeira oficina ocorreu em abril de 2015 , no município de São João do Polêsine e abordou a temática da educação ambiental. O público atingido foram estudantes e filhos de agricultores de uma escola estadual localizada no município. Os principais assuntos abordados foram os alimentos saudáveis, o uso de agrotóxicos e os impactos e riscos ambientais. Posteriormente, as crianças elaboraram materiais para compartilhar o conteúdo com os pais. Por fim, realizou-se uma avaliação da oficina em forma de desenhos, onde se pôde avaliar o conteúdo abordado e as impressões dos participantes sobre o tema, onde a maioria posicionase contrária ao uso de agrotóxicos.

Em maio de 2015, foi realizada a segunda oficina, no município de Dona Francisca, onde o objetivo central foi a socialização da experiência de uma família de assentados da reforma agrária do município de Júlio de Castilhos, na produção de hortaliças orgânicas. No primeiro momento, a família contou seu histórico na ocupação do agroecossistema e as atividades que desenvolvem. Esta família reside em um dos assentamentos do município e vem sendo uma das referências na produção ecológica de alimentos a cerca de 20 anos no município e, recentemente, na região. Após este primeiro contato entre os agricultores, todos foram convidados a conhecerem uma área do município, onde através de uma prática de organização dos canteiros da horta, puderam dialogar e trocar conhecimentos. Neste momento, a família abordou temas como, por exemplo, a organização e arranjo dos canteiros, época de plantio, manejo do solo, e técnicas naturais de controle de insetos e animais. Cabe ressaltar que a entidade parceira, ao chamar o público alvo, optou por agricultores vulneráveis economicamente e atendidos pelo programa Brasil Sem Miséria, a fim de incentivá-los a iniciar a atividade.

A terceira oficina foi realizada no município de Santa Maria, no mês de junho de 2015, na propriedade de uma família de agricultores cuja principal atividade é a pecuária leiteira, os animais são manejados com homeopatia e através do Pastoreio Racional Voisin (PRV). A família apresentou 0 histórico do agroecossistema, apresentando dados de produção de antes e depois do PRV ser implantado. Através de uma caminhada guiada, os produtores demonstraram como se dá a organização dos piquetes no PRV, como funciona o sistema de rotação, as pastagens utilizadas em cada piquete e sua relação com a época em que o gado o ocupa. Também foi exposto o local onde é realizada a ordenha e os equipamentos utilizados para realizar a atividade, o local onde o leite é armazenado e o manejo com os bezerros. Os agricultores também fazem uso de produtos homeopáticos para o tratamento de doenças nos bovinos.

Em outro momento, no mês de agosto do ano de 2015, foi realizada outra oficina no município de São João do Polêsine, em uma propriedade indicada pela 
Emater/RS-Ascar, cuja especialidade da família é a fruticultura. Um dos agricultores ecologistas de Santa Maria que faz parte das ações do NEA-UFSM foi convidado para compartilhar de sua experiência com fruticultura orgânica. A ação ocorreu em dois momentos, sendo que o primeiro teve caráter introdutório, onde os agricultores puderam ser apresentados uns aos outros e, também, conhecer a experiência da família anfitriã. Neste momento, o agricultor fez uma demonstração técnica de como preparar a calda bordalesa e pasta bordalesa, ambas muito utilizadas na fruticultura. No segundo momento, o agricultor convidado contou sobre a sua experiência e realizou demonstrações práticas de poda em pessegueiro, figueira, caquizeiro e goiabeira no pomar da propriedade, contando com a colaboração dos participantes.

As últimas duas oficinas foram realizadas na Universidade Federal de Santa Maria, em setembro, e surgiram a partir de um diagnóstico participativo com a finalidade de promover um retorno das análises de solo e água coletadas nos agroecossistemas das famílias acompanhadas, dividida em dois módulos sobre Qualidade e potabilidade da água e sobre Análise físico-química de solos. Como essa última etapa se caracterizou como uma apresentação de resultado técnicocientífico, foram convidados facilitadores que apresentaram e discutiram os resultados com os agricultores.

$\mathrm{Na}$ oficina tema Qualidade da água dois estudantes foram convidados para compartilhar seu conhecimento sobre a importância da potabilidade da água na agricultura familiar. Os facilitadores apresentaram um resumo sobre os componentes biológicos encontrados na análise de água, os parâmetros de potabilidade e os problemas de saúde causados pela ingestão de microrganismos patogênicos. Também foram apresentadas medidas de garantia da potabilidade, proteção de nascentes e formas de prevenção à contaminação. Neste momento, os agricultores analisaram e avaliaram seus agroecossistemas, a partir das análises laboratoriais, das práticas e dos usos.

Da mesma forma, o espaço sobre Análise físico-química de solos, facilitado por um doutorando em Ciência do Solo, foi realizado no sentido de avaliar as análises de solos das propriedades. O estudante também apresentou um resumo sobre os principais elementos na composição dos solos e sua importância para o desenvolvimento das plantas além de evidenciar a importância do manejo adequado para a manutenção da sustentabilidade dos solos. As oficinas foram construídas de modo participativo, a partir da solicitação dos agricultores e respeitando suas intervenções e relatos como forma de construção do conhecimento agroecológico. Da mesma maneira, puderam avaliar e discutir sobre suas práticas, com base nos dados laboratoriais e nas suas percepções e experiências.

\section{RESULTADOS E DISCUSSÃO}

As oficinas realizadas foram uma aproximação à metodologia Campesino a Campesino e também um processo de aprendizagem para os integrantes do grupo e para os agricultores. Enquanto que, para os estudantes, a iniciativa representou uma inovação metodológica e conceitual de extensão rural, para os agricultores, representou uma forma diferenciada de aprendizado: horizontal e mais próximo da sua realidade. Isso porque os temas escolhidos para as oficinas seguiram as orientações e necessidades dos próprios agricultores ecologistas que participaram do projeto, além do que a maioria dos ministrantes das oficinas eram os agricultores.

Ao adquirir um caráter educativo, esta experiência contribui na formação diferenciada dos futuros profissionais das ciências rurais e humanas, pois o maior contato com a realidade certamente capacita-os para interpretar e agir em situações complexas (THIES; MELLO, 2012). A maior parte das ações ocorreu no meio rural, 
nas propriedades dos agricultores participantes, fazendo com que os estudantes envolvidos pudessem conhecer a realidade rural da região e familiarizar-se com o trabalho da extensão rural. Além do mais, a aproximação das famílias de agricultores com os integrantes do NEA-UFSM proporcionou um avanço na troca de conhecimentos e na construção do conhecimento agroecológico. Para Caporal (2003) esse modelo teórico-pedagógico baseado no construtivismo é que possibilita a visão diferenciada para os profissionais que estarão adentrando ao mercado de trabalho posteriormente. Sendo assim, o NEA-UFSM cumpre um papel importante também na formação de uma ATER diferenciada, onde existe o respeito pelo agricultor, com seus saberes e conhecimentos que são centrais para o processo de desenvolvimento sustentável.

Nestas oficinas, ao todo, participaram cerca de 70 agricultores de diversos municípios da região central do RS, além de 30 estudantes, professores e técnicos. Estimulou-se que os ministrantes das oficinas fossem os próprios agricultores, que possuíam uma experiência de maior tempo com o tema proposto. Este fato foi importante para desenvolver nos agricultores a função de educadores, além de educandos, o que se aproxima da concepção freiriana de extensão, comunicação e educação no rural (FREIRE, 1983). Para os técnicos e professores foi importante para fomentar a discussão sobre o papel de educador e da relação dialógica da construção do conhecimento e colocá-los na condição de educandos.

Os encontros e oficinas possibilitaram a troca de saberes entre as famílias agricultoras e a discussão sobre temas que os sensibilizam, não só sobre o tema de cada uma das oficinas, mas como questões que surgiam naturalmente no diálogo, tais como o processo de comercialização, soluções para um problema fitossanitário, entre outras. Neste sentido, reforça-se a necessidade de criar espaços de encontros não rígidos e mais próximos da realidade dos participantes, que proporcione 0 diálogo e a interação, pois são momentos fundamentais para o processo de construção do conhecimento, visto que proporciona aos agricultores refletir sobre as questões locais utilizando a experiência de vida, suas e de seus pares. Como a maioria das oficinas foram realizadas nos agroecossistemas, priorizou-se pela realização de atividades práticas, para criar um ambiente mais informal de troca de conhecimento. Este ambiente proporcionou liberdade para que a interação ocorresse naturalmente, o que foi percebido desde as primeiras atividades, pois a interação continuou e fortaleceu-se ao longo das ações.

Neste momento, nascia uma rede de contatos que não terminou com o fim das atividades do NEA-UFSM. Estes agricultores continuam a trocar informações, dicas e ideias, o que vêm abrindo novos horizontes para os agricultores ecologistas da região central do RS. Neste último ano, parte dos agricultores obteve a Certificação como produtores orgânicos, a partir dos princípios agroecológicos, através da Organização de Controle Social (OCS) Coração Agroecológico, os quais integram a feira ecológica regional, denominada Ana Primavesi. Esta feria vem se mostrando um espaço de resistência e de promoção do consumo consciente, ético e sustentável, que conta com a participação dos agricultores acompanhados pelo NEA-UFSM e com a colaboração institucional da Universidade Federal de Santa Maria.

Considerando que a transição agroecológica é um processo gradual e multilinear de mudança (CAPORAL; COSTABEBER, 2004; COTRIM; DAL SOGLIO, 2016) entende-se que cada agroecossistema apresenta um caminho, o qual confere identidade e singularidade a cada uma dessas experiências e o diálogo entre os atores estimula a observação, a reflexão e a experimentação nos agroecossistemas. Diante desta concepção e desta experiência pode-se compreender que estas 
interações, promovidas pelas oficinas baseadas na metodologia CAC, podem contribuir, também, com a transição agroecológica.

Entretanto, mesmo com todo o esforço realizado, no sentido de reunir o maior número de agricultores para participar dos encontros, muitos entraves surgiram no período de organização das oficinas. Um deles é a questão da distância entre os agricultores, que dificultou a efetiva participação, já que o território central do RS é muito amplo em extensão. Santa Maria está localizada na porção central da região, e pela sua localização privilegiada, foi onde se desenvolveram a maior parte das oficinas e onde a sede do projeto está localizada, facilitando, também, a locomoção da equipe.

Além disso, há uma resistência por parte da comunidade acadêmica e dos técnicos extensionistas em participarem destes espaços. Está no imaginário popular que os conhecimentos são construídos no meio científico e na universidade, existindo uma desvalorização do que é empírico e do saber tradicional. Mais grave, e mais impactante nesta experiência, foi a resistência dos técnicos extensionistas com esta metodologia.

Entre os técnicos extensionistas e pesquisadores da área há uma avaliação de que o CAC é realizado em países onde não existe uma equipe técnica suficiente ou que estes não estão capacitados para atuar e atender as demandas dos agricultores. Esta afirmação pré-concebida nasce do fato que, na verdade, poucos são os técnicos e pesquisadores que conhecem a metodologia e seus princípios. Ademais, tal afirmação não procede, haja vista as experiências exitosas em nível de política de desenvolvimento rural nacionais, como é o caso de Cuba e da Nicarágua.

Essa resistência pode ser explicada pela formação acadêmica orientada para uma extensão rural difusionista, que entende o extensionista rural como um canal entre o pesquisador que produz o conhecimento e o receptor que recebe a tecnologia ou o conhecimento. Para Perera e Costa Gomes (2009) esta concepção aumenta o distanciamento entre o pesquisador, extensionista e o agricultor e molda estruturalmente as instituições de extensão e pesquisa no Brasil. Para os autores, a emergência de uma extensão agroecológica e do uso de metodologias participativas tende a diminuir estas fragmentações, embora estejam institucionalmente presos a esta concepção hierárquica da detenção do conhecimento por parte dos técnicos e pesquisadores.

Caporal (2003) salienta que o modelo de educação favorece a sobreposição do conhecimento científico ao do agricultor, impondo um modelo capitalista de agricultura. Por isso, o autor afirma que é necessária a emergência de um "novo profissionalismo" marcado pela capacidade dos profissionais em enxergar as pessoas antes das coisas, atentando-se sempre aos menos favorecidos, além de saber que os métodos não são neutros. O modelo de desenvolvimento brasileiro, apesar dos avanços nos últimos anos, ainda tende a aproximar-se da prática da transferência de tecnologia, vertical e não-dialógica, onde o agricultor é o receptor ou adotante de determinada prática.

Desta forma, é preciso repensar o papel da assistência técnica e da extensão rural, onde seja valorizado e retomado o protagonismo dos agricultores e, para isso é necessário resgatar princípios como o diálogo e a horizontalidade, características estas, exigidas por quem está orientado pela ciência agroecológica, sobretudo, àqueles que se propõem a trabalhar com a metodologia CAC.

No final de cada atividade houve momentos de avaliação por parte dos participantes, tanto como da metodologia como do assunto abordado. Os agricultores avaliaram de forma positiva a metodologia, contribuindo no intuito de melhorar a experiência e demonstraram interesse em participar noutros momentos. Inclusive, alguns se motivaram a apresentar as suas experiências para o grupo, 
enquanto outros ao experimentarem as novas ideias tornaram a socializar com o grupo, demonstrando que houve diálogo e motivação durante as atividades.

Uma das sugestões dos agricultores é que este tipo de ações, baseadas no CAC e no diálogo horizontal entre agricultores possa ser realizado continuadamente, o que infelizmente não foi possível ser realizado pelo NEA-UFSM, considerando que estas ações foram fruto de financiamento público, interrompidos nos últimos anos.

\section{CONSIDERAÇÕES FINAIS}

O desenvolvimento das oficinas propostas pelo NEA-UFSM possibilita concluir que é primordial repensar as metodologias utilizadas na pesquisa e na extensão agroecológica. Podemos destacar que as seis oficinas realizadas, com base na metodologia Campesino a Campesino, objetivaram aproximar o agricultor de outros atores no intuito de promover uma experiência de empoderamento em que o agricultor se reconhece enquanto agente transformador de sua realidade, capaz de criar e de experimentar novos caminhos rumo à sustentabilidade dos agroecossistemas.

Espera-se que esta experiência, que se coloca como pioneira no território central do RS ao utilizar o CAC como referência metodológica, possa inspirar reflexões na comunidade acadêmica, na pesquisa e extensão acerca dos métodos utilizados na pesquisa agroecológica e em efetivamente considerar o agricultor enquanto um agente de desenvolvimento.

Há muitos entraves quanto à plena execução desta metodologia no território central do RS. A principal é a resistência dos técnicos extensionistas a considerarem o papel ativo do agricultor, como ser capaz de experimentar, refletir e socializar seus conhecimentos e anseios de forma crítica, criativa e efetiva na resolução diária dos problemas.

Neste sentido, ressalta-se a importância da experiência para os atores envolvidos, bem como para o desenvolvimento rural sustentável. Ao utilizar o CAC, a experiência permitiu às famílias agricultoras a possibilidade de identificar alternativas exitosas para problemas de questão técnica e produtiva utilizadas em outros agroecossistemas. Assim, destaca-se que tal experimento contribuiu também para a dimensão econômica dos agroecossistemas.

No que diz respeito ao âmbito ambiental, constata-se a adequação das experiências registradas com a conservação dos recursos naturais, ao passo que essas, ao adotarem os princípios agroecológicos, não interferem de forma tão agressiva no ambiente como as constatadas no molde produtivista.

Desta forma, através da experiência relatada, constata-se sua real contribuição para o desenvolvimento rural sustentável, em suas múltiplas dimensões, bem como aponta alternativas para uma extensão rural agroecológica que possibilite o protagonismo das famílias agricultoras, alicerçado no trabalho de técnicos, estudantes e comunidade em geral.

\section{REFERÊNCIAS}

ALTIERI, M.; NICHOLLS, C. I. Agroecologia: teoria y práctica para uma agricultura sustentable. PNUMA: México. 2000.

ALTIERI, M.; NICHOLLS, C. I. Agroecologia, resgatando a agricultura orgânica a partir de um modelo industrial de produção e distribuição. Revista Ciência e Ambiente, Santa Maria: UFSM, v.27, jul./dez 2003. 
ALTIERI, M. Agroecologia: bases científicas para uma agricultura sustentável. 3. ed. Rio de Janeiro: Expressão Popular, 2012.

BORGES, J. L. Movimentos Sociais e Sustentabilidade: os desafios da "Extensão Rural Agroecológica" em Assentamentos de Reforma Agrária. Revista Cesumar Ciências Humanas e Sociais Aplicadas, v. 17, p. 203-230, 2012.

CANUTO, J. C. Metodologia da pesquisa participativa em Agroecologia. São Luiz, Maranhão. EMBRAPA, abr. 2005.

CAPORAL, F. R. Bases para uma nova ATER pública. Extensão Rural, Santa Maria, v. 10, p. 1-20, jan./dez. 2003. Disponível em: https://periodicos.ufsm.br/extensaorural/article/view/5546/3271. Acesso em 23 set. 2019.

CAPORAL, F. R.; COSTABEBER, J. A.; PAULUS, G. Agroecologia: matriz disciplinar ou novo paradigma para o desenvolvimento rural sustentável. In: TOMMASINO, H.; HEGEDÜS, P. (Eds.). Extensión: reflexiones para la intervención en el medio urbano y rural. Montevideo: Departamento de Publicaciones de la Facultad de Agronomía - Universidad de la República Oriental del Uruguay, 2006. p.45-64.

CAPORAL, F. R.; COSTABEBER, J. A. Agroecologia: enfoque científico e estratégico. Agroecologia e Desenvolvimento Rural Sustentável. Porto Alegre, v.3, n.2, abr/jun, 2002.

CAPORAL, F. R.; PERTERSON, P. Agroecologia e Políticas Públicas na América Latina: o caso do Brasil. Agroecología, v. 6, p. 63-73, 2012.

CAPORAL, F. R.; DAMBROS, O. Extensão Rural Agroecológica: experiências e limites. REDES: Revista do Desenvolvimento Regional, v. 22, n. 2, p. 275-297, 2017.

COSTA GOMES, J. C. Pesquisa em Agreocologia: problemas e desafios. In: AQUINO, A. M. de; ASSIS, R. L. de. (Org.). Agroecologia: princípios e técnicas para uma agricultura orgânica sustentável. Brasília-DF: Embrapa Informação Tecnológica, 2005, p. 133-144.

COTRIM, D. S.; DAL SOGLIO, F. K. Construção do Conhecimento Agroecológico: Problematizando a noção. Revista Brasileira de Agroecologia, v. 11, n. 3, p. 259271,2016

COTRIM, D. S. Método participativo: uma análise a partir de uma perspectiva agroecológica. Revista Brasileira de Agroecologia, v. 12, n. 4, p. 255-267, dez. 2017.

DAL SOGLIO, F. K. Princípios e Aplicações da Pesquisa Participativa em Agroecologia. REDES: Revista do Desenvolvimento Regional, v. 22, n. 2, p. 116 136, 2017.

FREIRE, P. Extensão ou comunicação? 7.ed. Rio de Janeiro: Paz e Terra, 93 p. 1983. 
GLIESSMAN, S. R. Agroecologia: processos ecológicos em agricultura sustentável. Porto Alegre: Editora UFRGS, 2000.

GLIESSMAN, S. R. Agroecología y Agroecossistemas. Ciência e Ambiente. Jul./dez., 2003.

GLIESSMAN, S. R.; et. al. Agroecología: promoviendo una transición hacia la sostenibilidad. Ecossistemas, v. 16, p. 13-23, 2007.

GIMÉNEZ, E. H. Campesino a campesino: voces de latinoamérica Movimiento Campesino para la agricultura Sustentable. Managua: SIMAS, 2008.

GUZMÁN, E. S. Uma estratégia de sustentabilidade a partir da Agroecologia. Agroecologia e Desenvolvimento Rural Sustentável, Porto Alegre, v.2, n.1, jan./mar, 2001, p. 35 - 45.

HERNÁNDEZ, J. M. La crisis global y sus impactos en la vida rural. In: HERNÁNDEZ, J. M. (coord.). La Agroecologia en la construcción de alternativas hacia la sustentabilidad rural. México: Siglo. XXI Ed./Instituto Tecnológico e de Estudos Superiores do Ocidente, 2011. p.17-50.

KAUFMANN, M. P., et al. Processo de ecologização das propriedades rurais dos municípios compreendidos pelo Território Central do Estado do Rio Grande do Sul (Programa Terra Sul). In: SILVA, H. B C.; CAVALCANTI, D.C.; PEDROSO, A. F. Pesquisa e Extensão para a Agricultura Familiar. Brasília: Secretaria da Agricultura Familiar - Ministério do Desenvolvimento Agrário, 2015. cap. 7, p. 217224.

MACHÍN, B. El movimiento agroecológico de campesino a campesino en sus 20 años de implementación en cuba. Realidades, realizaciones y retos. Agroecología, v. 12, n. 1, p. 99-105, 2017.

MELO, A. M.; PINHEIRO, D. C. Uma discussão da eficiência na literatura da extensão rural: limites e proposições conceituais. Extensão Rural, Santa Maria, v. 24, n. 3, p. 7-23, jul./set. 2017. Disponível em: https://periodicos.ufsm.br/extensaorural/article/view/25035/pdf. Acesso em: 23 set. 2019.

MINISTÉRIO DO DESENVOLVIMENTO AGRÁRIO (MDA). Sistemas de Informações Territoriais. Brasília - DF, 2012. Disponível em: http://sit.mda.gov.br. Acesso em: 17 nov. 2016.

PERERA, A. F.; GOMES, J. C. C. O uso de metodologias participativas na democratização do conhecimento: avaliação de rede de referência na Região Sul do RS. Extensão Rural, Santa Maria, v. 16, n. 18, p. 123-146, jul./dez. 2009. Disponível em: http://w3.ufsm.br/extensaorural/art5ed18.pdf. Acesso em: 22 dez. 2019.

SOSA, B. M.; JAIME, A. M. R.; LOZANO, D. R. A.; ROSSET, P. M. Revolução agroecológica: o movimento de camponês a camponês da ANAP em Cuba. ANAP. 2011. 
SILIPRANDI, E. Desafios para a extensão rural: o social na transição agroecológica. Agroecologia e Desenvolvimento Rural Sustentável, Porto Alegre, v. 3, n.3, p. 38-48, 2002.

THIES, V. F.; MELLO, U. P. Procedimentos educativos de transição agroecológica: o caso da experimentação participativa na FUNDEP (RS). Extensão Rural, Santa Maria, v. 19, n. 2, p. 109-126, abr./jun. 2012. Disponível em: https://periodicos.ufsm.br/extensaorural/article/view/8139/4877. Acesso em: 23 set. 2019. 